\title{
Adaptive Neuro-fuzzy Controller for Multi-layered Switched Reluctance Motor
}

\author{
Wafaa A. Arakat \\ Researcher at Computer and \\ Systems Department, Faculty \\ of Engineering, Mansoura \\ University
}

\author{
Amira Y. Haikal \\ Lecturer at Computer and \\ Systems Department, Faculty \\ of Engineering, Mansoura \\ University
}

\author{
Ayman H. Kassem \\ Associate Professor at \\ Aerospace Department, Faculty \\ of Engineering, Cairo University
}

\begin{abstract}
There has been big interest in switched reluctance motor (SRM) due to its simplicity and reasonable cost, however excessive torque ripple is one of the major disadvantages of switched reluctance motor. This paper attempts to reduce torque ripples of Switched Reluctance Motor through building multi-layered motor controlled by a hybrid intelligent system known as Adaptive Neuro-fuzzy Inference System ANFIS. Simulation of the proposed motor is conducted using Matlab Simulink environment 2011 and comparison results with single layer switched reluctance motor for both PI and ANFIS controllers show improvement in behavior of MSRM controlled by ANFIS through reduction in speed settling time as well as torque ripples.
\end{abstract}

\section{General Terms}

Electrical Machines; Adaptive Control.

\section{Keywords}

Multi-layer switched reluctance motor; SRM; Torque ripples; ANFIS.

\section{INTRODUCTION}

SRM has received attention due to its inherent simplicity, ruggedness, and low cost. These features make it a good candidate for various general purpose adjustable speed applications [1].

The most unique feature of SRM is its double saliency structure which means both stator and rotor has salient poles. The stator winding has concentrated coils, and shorter end turns than other types of motors, leading to a greater manufacturing economy. Moreover the salient rotor has no conductors or magnets, as shown in fig. 1. The rotor turns to get to a position of minimum reluctance by aligning itself with the stator magnetic field when the stator windings are excited, it is thus considered as the simplest of all electric machine rotors[1],[2].

Simplicity of the construction of SRM makes it inexpensive, the windings are electrically separate from each other which make the machine reliable, and cooling is simpler because the major sources of heat are on the stator. In addition, high speed capability of SRM and high torque to inertia ratio makes it a superior choice in different applications. However, Excessive torque ripple, especially at low speeds prevented SRM from widespread use [3].

Actually there are two approaches to reduce torque ripples: one of them is to improve the magnetic design of the motor, by changing the stator and rotor pole structures [4]. ElKharashi [5] used the hollow cylindrical rotor to reduce torque ripples. There was no shaft, and the cylindrical rotor was designed to grade the air gap, and consequently the reluctance; which reduced ripples in the torque characteristic. Shang and Shing [6] changed the stator shape to c- shape one, the c-shape created more space for winding and hence became more straightforward, it had more number of turns per phase than traditional SRM; as a result the motor gave higher torque for the same current than in traditional SRM and consequently, minimize the cost of the motor. Daldaban and Ustkoyuncu [7] introduced multi-layer SRM. Their design allowed more space for stator winding and higher starting torque than classical SRM of the same size. The noise was reduced as well as torque ripples.

The second approach is to use sophisticated electronic control. The electronic approach is based on selecting an optimum combination of the operating parameters, such as supply voltage, turn on and turn off angles and level of current [4].

Rodrigues et al. [8] implemented fuzzy logic controller for reducing torque ripples through turn off angle. Zhang et al. [9] also used fuzzy controller to compute the current compensating signal that added to the main current value in order to reduce torque ripple. While Shang et al. [10] introduced flux-linkage controller using sliding mode technique (SM) with integral compensation (I). The integration of SM with I controller result in reduction of torque ripples when compared to each method alone.

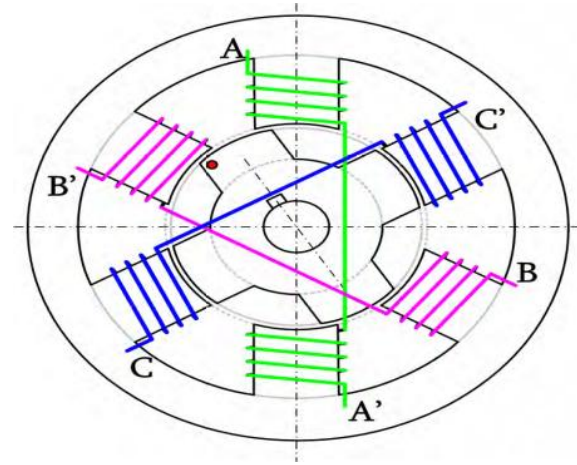

Fig. 1: 6/4 switched reluctance motor

The most common approach used for the reduction of torque ripples is the second one; because changing motor design can affect the performance such as restrict excessively the speed band operation of the SRM [1]. Actually Due to special structure and switching operation, SRM has highly nonlinear characteristics; the flux linkage is a nonlinear function of both current and rotor position as shown in fig. 2. Therefore, the 
use of classical controllers does not meet the requirements of the robust performance [11].

There has been an increasing interest in the development of an efficient control strategy to improve dynamic behavior of the SRM by using various hybrid intelligent controllers [11], [12].

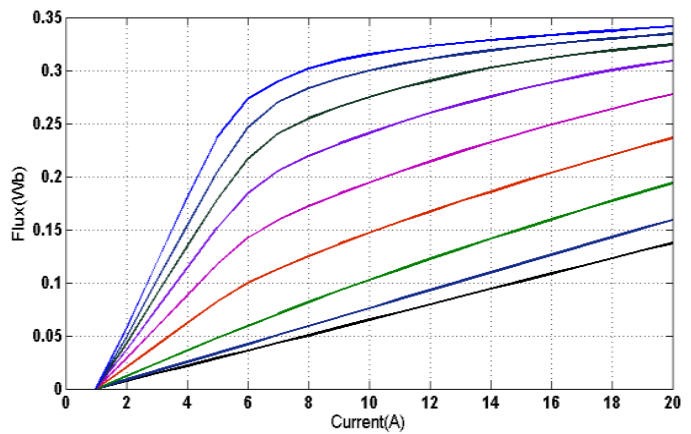

Fig. 2: Flux Linkage for SRM

What we are proposing in this paper is a framework combining the two different approaches to reduce torque ripples of a SRM. The proposed framework tries to modify the SRM's design by presenting a multi-layered SRM (MSRM) as well as using an intelligent adaptive controller to gain better performance with the addition of the current compensation method that leads to better reduction of torque ripples.

Next sections are as follows. Section 2 describes the main features of SRM. MSRM was introduced in addition to the basic idea of the controller in section 3. Section 4 describes ANFIS as the proposed controller. Section 5 shows the detailed model built in Matlab Simulink.

Finally, section 6 illustrates simulation analysis testing the proposed framework on both SRM and MSRM and compares it with classical PI controller.

\section{SWITCHED RELUCTANCE MOTOR}

When stator phase is excited it attracts the nearest rotor poles so that the reluctance reaches a minimum value. Therefore rotor position should be known in order to choose the proper phase to be excited when operating the motor. For this reason position sensor usually used for SRM.

For 6/4 SRM only two poles used for torque production, and if the rotor poles was in unaligned position the motor will not start at full load because of insufficient starting torque [7] ,[13].

To avoid this problem, increasing the number of rotor and stator poles should be considered as one solution to the problem which will also minimize the torque ripples. Actually in order to involve four poles in the torque production mechanism; one need to have a 12 /8 motor, and when motor size is reduced, availability of space for windings becomes an issue. One method to solve this problem were presented by Afjei [13] through distributing the stator poles along the length of the motor by having different independent sections or phases where each phase has the same number of rotor and stator poles producing the MSRM. Actually, (MSRM) is the prime interest of most researchers to solve insufficient starting torque problem [7], [13].

\section{MULTI-LAYERED RELUCTANCE MOTOR}

SWITCHED

MSRM was presented by Afjei [13] the motor consists of three magnetically independent layers. Both stators and rotors have eight salient poles with $60^{\circ}$ angular shifts between each consecutive pole.

Another MSRM was presented by F.Daldaban, and $\mathrm{N}$. Ustkoyuncu [7]. Their MSRM structure consists of two magnetically isolated layers. The stator and rotor parts of each layer have six and four poles, respectively. So the MSRM is realized with the combination of a conventional 6/4 SRM with three phases.

Each rotor part has a $15^{\circ}$ angular shift in position from the next layer, while in the stator, the phases are on the same position. The three dimensional appearance of the MSRM is illustrated in fig. 3 [7]

The proposed framework in this article analyzes the performance of the MSRM presented by [7] after controlling it using adaptive neuro-fuzzy inference system (ANFIS).

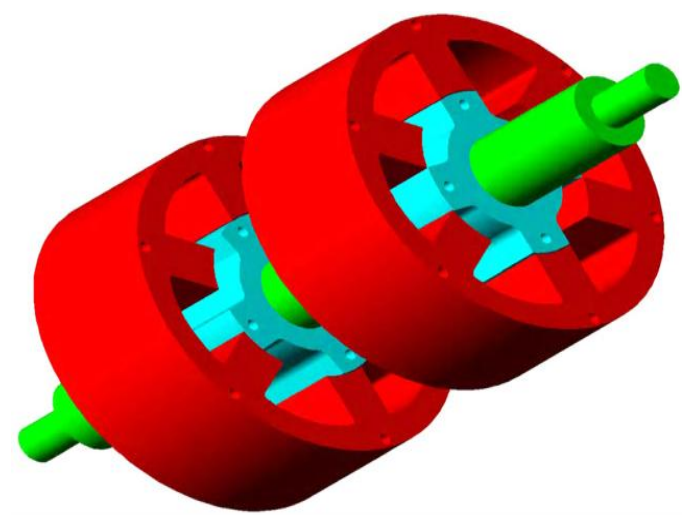

Fig. 3: Multi-layered switched reluctance motor [7]

The basic idea of the controller proposed here was presented by [11] which are to calculate compensating current $\Delta \mathrm{I}$, which is a small value of current. This compensating current is then added to the PI current output in order to feed the phase with the optimal current value that leads to minimum torque which is the main objective here, as shown in fig.4.

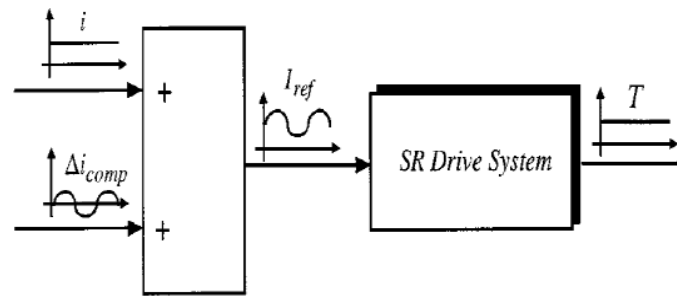

Fig. 4: Basic idea of compensation method [11]

\section{ADAPTIVE NEURO-FUZZY INFERENCE SYSTEM (ANFIS)}

A Neuro-fuzzy network is the combination of neural networks with the fuzzy logic; this combination has the explicit knowledge representation of a Fuzzy Inference System (FIS) with the learning power of ANNs.

FIS forms a useful computing framework based on the concepts of fuzzy set theory, fuzzy if-then rules and fuzzy reasoning. ANFIS is a FIS implemented in the framework of an adaptive fuzzy neural network [14], [15]. 
The main objective of ANFIS is to optimize the parameters of the equivalent FIS by applying a learning algorithm using input-output data sets. The parameter optimization is done in a way such that the error measure between the target and the actual output is minimized.

A typical architecture of an ANFIS for two inputs is shown in fig. 5 , in which a circle indicates a fixed node whereas a square indicates an adaptive node [14],[15]. Considering two inputs $\mathrm{x}, \mathrm{y}$ and one output $\mathrm{z}$ and a Sugeno-fuzzy model. Among many FIS models, the Sugeno fuzzy model is the most widely applied one for its high interpretability, computational efficiency, and built-in optimal and adaptive techniques [14], [16].

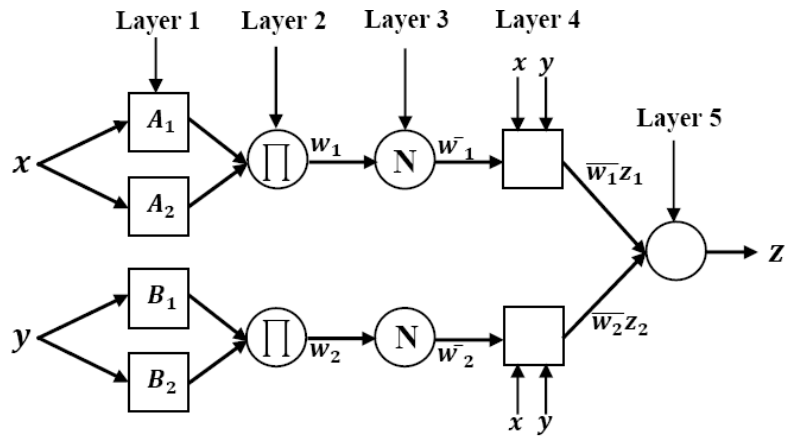

Fig. 5: Architecture of ANFIS

ANFIS consists of five layers the description of these layers is as follow:

Layer 1: Every node $\mathrm{i}$ in the first layer employ a node function given by:

$o_{i}^{1}=\mu_{A i}(x), i=1,2$

$o_{i}^{1}=\mu_{B i}(y), i=3,4$

Where $\mu_{A i}$ and $\mu_{B i}$ can adopt any fuzzy membership function (MF).

Layer 2: Every node in this layer calculates the firing strength of a rule via multiplication.

$o_{i}^{2}=w_{i}=\mu_{A i}(x) \mu_{B i}(y), i=1,2$

Layer 3: The i-th node in this layer calculates the ratio of the i-th rule's firing strength to the sum of all rules firing strengths:

$o_{i}^{3}=\overline{w_{i}}=\frac{w_{i}}{w_{1}+w_{2}}, i=1,2$

Where ${ }^{w_{i}}$ is referred to as the normalized firing strengths.

Layer 4: In this layer, every node i has the following function:

$o_{i}^{4}=\overline{w_{i}} z_{i}=\overline{w_{i}}\left(p_{i} x+q_{i}(y)+r_{i}\right), i=1,2$

Where $\overline{w_{i}} \quad$ is the output of layer 3 , and $\{\mathrm{p}, \mathrm{q}, \mathrm{r}\}$ are the parameter set. The parameters in this layer are referred to as the consequent parameters.
Layer 5: The single node in this layer computes the overall output as the summation of all incoming signals, which is expressed as:

$o_{i}^{5}=\sum_{i=1}^{2} \overline{w_{i}} z_{i}=\frac{w_{1} z_{1}+w_{2} z_{2}}{w_{1}+w_{2}}$

The output $\mathrm{z}$ in fig. 4 can be rewritten from equations [2]-[4] as:

$$
\begin{aligned}
& z=\left(\overline{w_{1}} x\right) p_{1}+\left(\overline{w_{1}} y\right) q_{1}+\left(\overline{w_{1}}\right) r_{1}+\left(\overline{w_{2}} x\right) p_{2}+ \\
& \left(\overline{w_{2}} y\right) q_{2}+\left(\overline{w_{2}}\right) r_{2}
\end{aligned}
$$

\section{MODELING OF SRM}

\subsection{Electromagnetic equations}

The instantaneous voltage across the terminals of a phase of a Switched Reluctance Motor winding is related to the flux linked in the winding by Faraday's law as [17]:

$$
V=I R+\frac{d \psi(i, \theta)}{d t}
$$

Where $\mathrm{V}$ is the terminal voltage, $\mathrm{I}$ is the phase current, $\mathrm{R}$ is the phase winding resistance, and $\psi \square \square$ is the flux linked by the winding.

While excluding saturation and mutual inductance effects, the flux in each phase is given by the equation:

$\psi(i, \theta)=L(\theta) I(i)$

Where $\mathrm{L}$ is the inductance and the motor total torque $\mathrm{T}$ is given by:

$T=\frac{1}{2} I^{2} \frac{d l}{d t}$

And

$w=\frac{d \theta}{d t}$

$T-T_{L}-f w=J \frac{d w}{d t}$

Where $\mathrm{T}$ is the electrical torque, $T_{L}$ is the load torque, $\omega$ is the angular speed, $\mathrm{f}$ is the coefficient of friction and $\mathrm{J}$ is the moment of inertia [1],[2].

From previous equations of SRM the model for simulation is developed. Fig. 6 shows simulink model for SRM, and fig. 7, shows the electrical model for one phase of the SRM.

Because of the double salience construction of the Switched Reluctance motor and the magnetic saturation effects, the flux linked in a SRM phase varies as a function of rotor position $(\theta)$ and the phase current $(i)$, and so the torque is a function of current and rotor position $T(i, \theta)$, equation (9).

Characteristics are computed and stored in a tabular form named as "Look-up Tables" to obtain the phase current and the phase torque as shown in fig. 8 , which shows torque characteristics for one phase of SRM for different level of currents. Fig. 9 shows the mechanical model of SRM which is described by equation (11). 


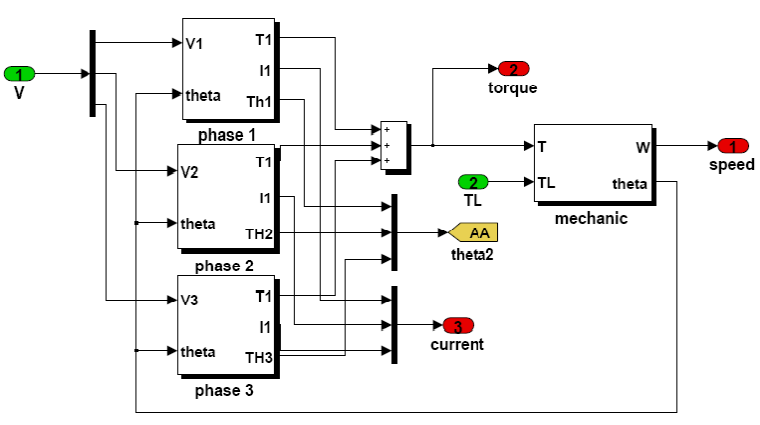

Fig. 6: SRM simulation model

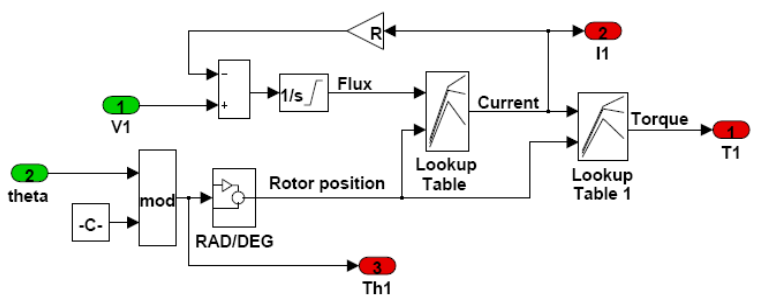

Fig. 7: Electrical model for one phase of SRM

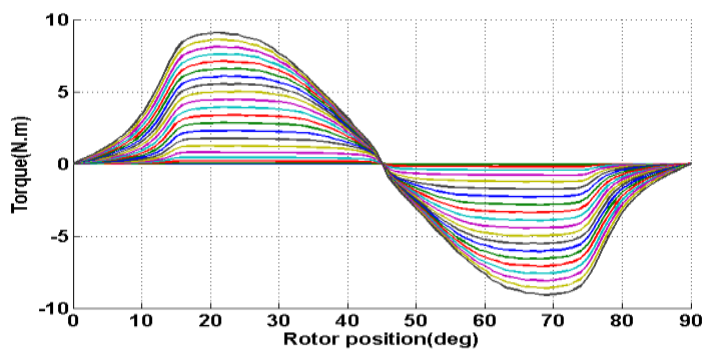

Fig. 8: Torque characteristics for one phase of SRM for different levels of currents
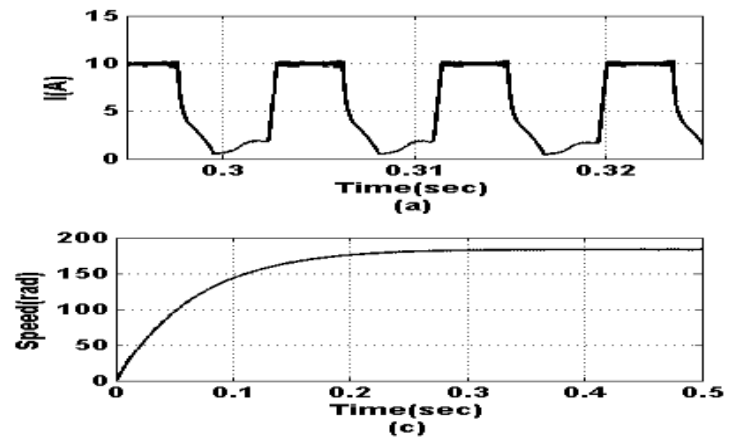

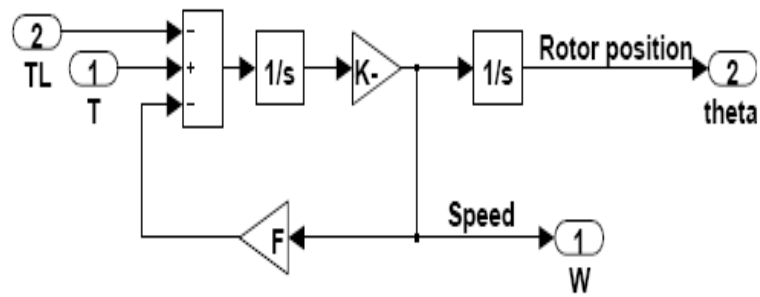

Fig. 9: Mechanical model of SRM

\section{SIMULATION RESULTS}

To verify the simulated model with [17], SRM operates in open-loop mode and for a set of operating conditions. Results in fig. 10 have been achieved for turn on angel $0^{\circ}$ and $40^{\circ}$ as turn off angle with reference current $10 \mathrm{~A}$, and without torque load.

To test the validity of the proposed framework, simulation of a nonlinear model of MSRM using ANFIS and current compensation method is conducted using Matlab Simulink 2011. Simulink model of the overall control system is shown in fig. 11

Motor specifications are listed in table 1. The rotor's angular position $\theta$ and the PI controller's output signal I ref, are used as inputs to the ANFIS compensator producing $\Delta \mathrm{I}$ as output signal as shown in fig. 12.The internal structure of the ANFIS controller is shown in fig. 13.

The neuro-fuzzy compensator is a Sugeno-type fuzzy logic system with five fixed triangular membership functions for each input as shown in fig $14(a, b)$.The training procedure evolves adjusting the rule consequents by a hybrid training algorithm, which combines back-propagation and least-square error minimization

Fig.10: SRM model: (a) current in phase 1, (b) torque in phase 1, (c) speed, and (d) total torque

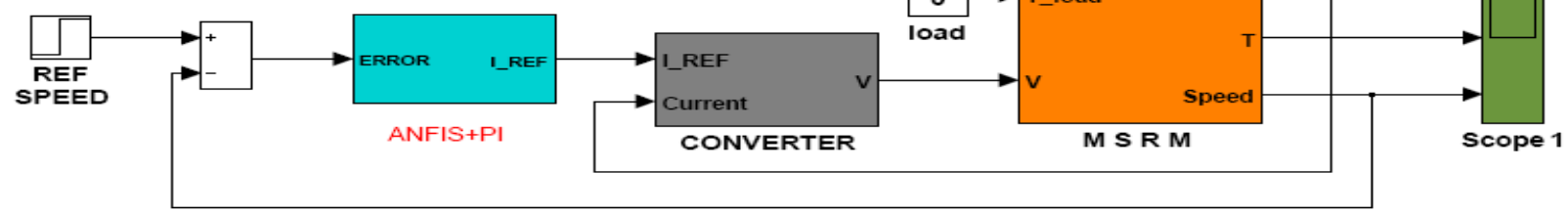

Fig.11: Simulink model of the overall control system 


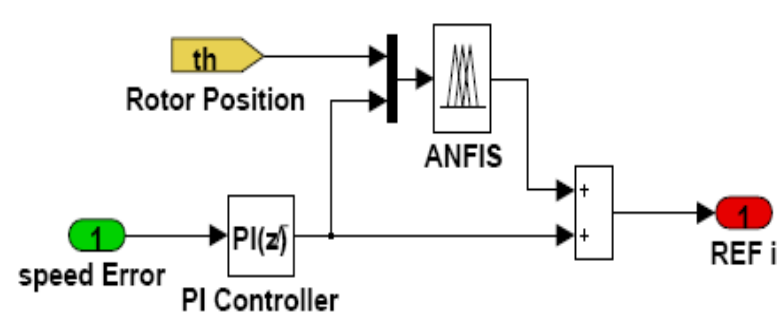

Fig. 12: ANFIS+PI controller for MSRM

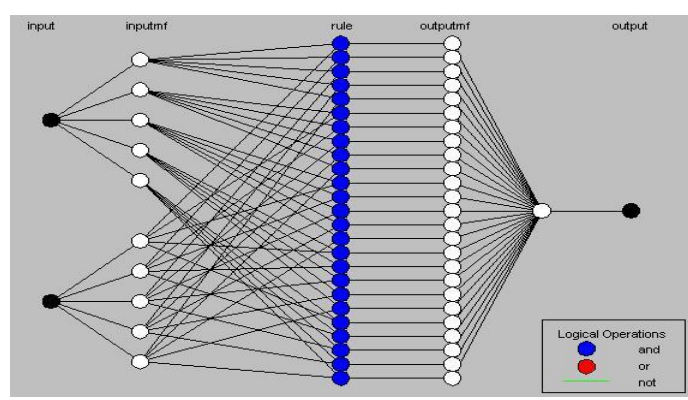

Fig. 13: The Neuro Fuzzy Controller Structure

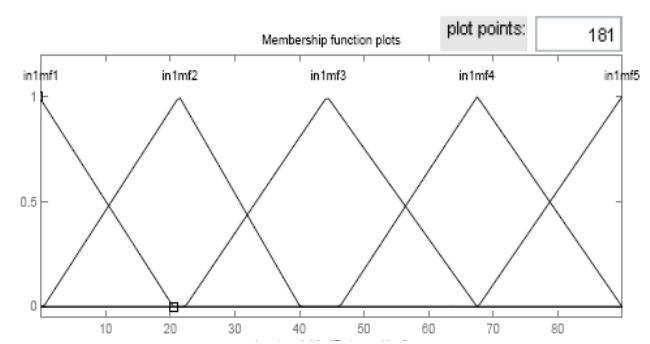

(a)

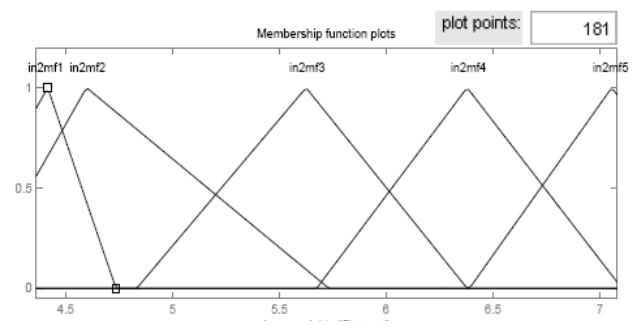

(b)

Fig. 14: (a) membership functions for rotor position theta $(\theta)$, (b) PI reference current (I ref)

Simulation analysis is implemented to compare the behavior of the stand alone classical PI controller with the proposed framework for both MSRM and classical SRM at $500 \mathrm{rpm}$ as reference speed and with no load.

\subsection{PI controller}

Using a classical PI controller with speed error as input and current as an output, fig. 15 shows torque ripples at steady state for classical SRM, while fig.16 shows torque ripples at steady state for MSRM. Fig. 17 shows speed response for both classical SRM and MSRM.

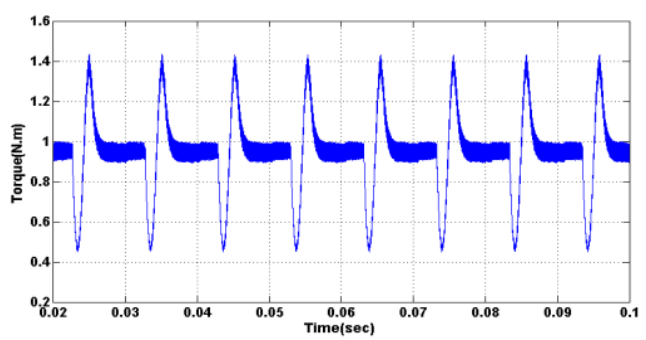

Fig. 15: Torque for classical SRM after steady state

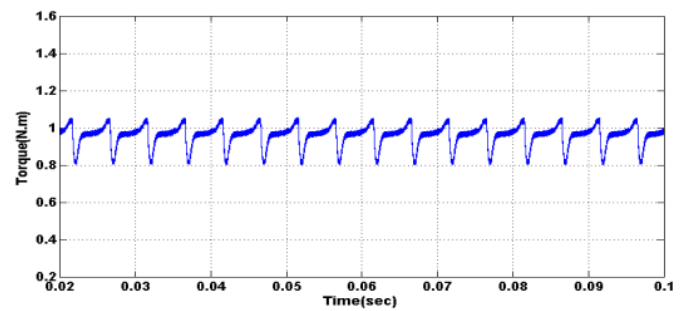

Fig. 16: Torque for MSRM after steady state

As noticed from fig. 15, 16 the highest component of torque ripple occurs at region of switching currents between phases and these figures illustrate the reduction in torque ripples when using MSRM controlled by PI controller. Moreover, speed behavior of MSRM is also improved compared with SRM as depicted in fig. 17.

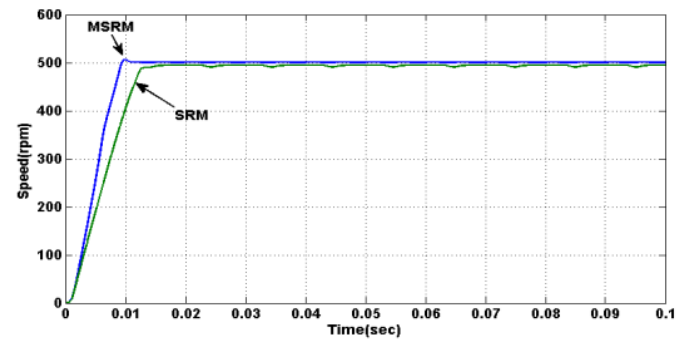

Fig.17: Speed for both SRM and MSRM at $500 \mathrm{rpm}$ as reference speed

\subsection{ANFIS PLUS PI CONTROLLER}

Simulation analysis is retested on both classical SRM and MSRM for the proposed framework including ANFIS plus PI controller. Fig. 18 shows torque ripples at steady state for SRM, while fig.19 shows torque ripples at steady state for MSRM. Fig.20 illustrates the speed for both SRM and MSRM.

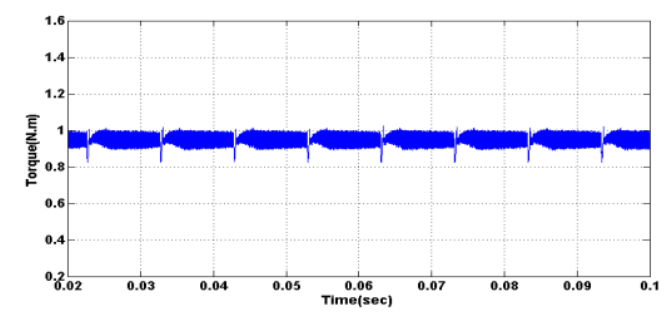

Fig. 18: Torque ripples for SRM at steady state 


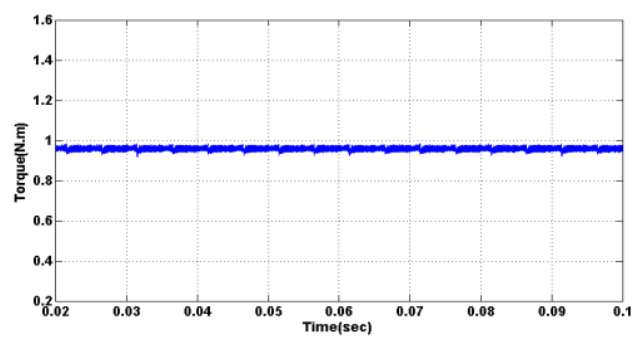

Fig. 19: Torque ripples for MSRM at steady state

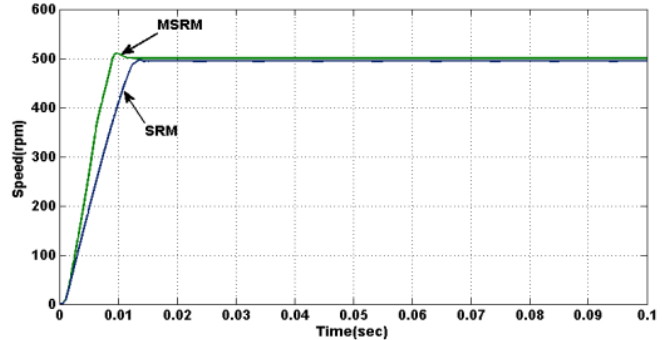

Fig.20: speed for both SRM and MSRM at $500 \mathrm{rpm}$ as reference speed

It is obvious that the speed of MSRM shows faster response than classical SRM when using PI controller as well as ANFIS. However, the speed response for SRM and MSRM using both controllers almost the same.

Comparison of the proposed controller with classical PI controller for both MSRM and classical SRM shows great reduction in torque ripples. The detailed comparison results for torque ripples at steady state and settling time are presented in Table 2.

\section{Table (1): Motor features}

\begin{tabular}{|c|c|}
\hline Features & Values \\
\hline Number of layers & 2 \\
\hline Number of stator poles & 6 \\
\hline Number of rotor poles & 4 \\
\hline Phase resistance ( R) & $1.3 \Omega$ \\
\hline Phase current & $15 \mathrm{~A}$ \\
\hline Phase voltage & $150 \mathrm{~V}$ \\
\hline Moment of inertia $(\mathrm{J})$ & $0.0013\left(\mathrm{~kg} . \mathrm{m}^{2}\right)$ \\
\hline Friction $(\mathrm{F})$ & $0.0183(\mathrm{~N} \cdot \mathrm{m} / \mathrm{s})$ \\
\hline
\end{tabular}

Table (2): Comparison results between classical PI and ANFIS controllers.

\begin{tabular}{|c|c|c|c|}
\hline Controller & Motor & $\begin{array}{c}\text { Torque } \\
\text { Ripple }\end{array}$ & $\begin{array}{c}\text { Speed } \\
\text { Settling time } \\
\text { (sec) }\end{array}$ \\
\hline \multirow{2}{*}{$\begin{array}{c}\text { Classical PI } \\
\text { controller }\end{array}$} & SRM & 1.06 & 0.016 \\
\cline { 2 - 4 } & MSRM & 0.26 & 0.012 \\
\hline $\begin{array}{c}\text { ANFIS+PI } \\
\text { (proposed } \\
\text { framework) }\end{array}$ & SRM & 0.21 & 0.015 \\
\cline { 2 - 4 } & MSRM & 0.07 & 0.012 \\
\hline
\end{tabular}

\subsection{Motor performance}

The characteristics of MSRM drive system are evaluated for $1500 \mathrm{rpm}$ as reference speed the resulted torque curve after steady state is shown in fig. 21 while fig. 22 shows speed response.

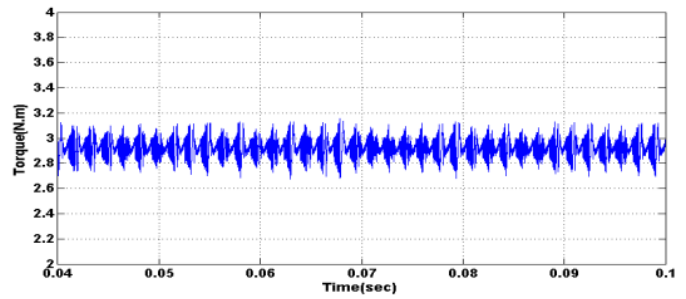

Fig. 21: Torque ripples for MSRM at steady state

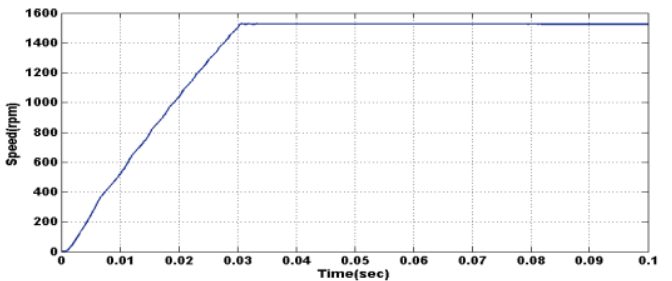

Fig.22: Speed response of MSRM at $1500 \mathrm{rpm}$ as reference speed

It is noticed form the previous figures that the ANFIS has good performance since the torque ripples is 0.164 from the average value and speed settling time is $0.03 \mathrm{sec}$ which are good results for high speeds.

\section{CONCLUSIONS}

In this paper, an adaptive neuro-fuzzy controller for the MSRM based on the ANFIS algorithm is presented.

First order sugeno type fuzzy inference system is used with five membership triangular functions being used for both controller inputs $\left(\theta, i_{r e f}\right)$ their parameters are optimized by ANFIS.

Comparison results with single layer switched reluctance motor for both PI and ANFIS show improvement in steady state behavior of MSRM controlled by ANFIS through reduction in speed settling time and torque ripples. Moreover the ANFIS controller has good performance at high speeds.

\section{REFERENCES}

[1] T.E Miller, "Switched reluctance motors and their control”, Oxford: Oxford University Press; 1993.

[2] R. Krishnan, "Switched Reluctance Motor Drives Modeling, Simulation, Analysis, Design, and Applications", CRC Press, 2001.

[3] I. Husain, "Minimization of Torque Ripple in SRM Drives", IEEE Trans. Ind. Electronics, vol.49, No.1, pp. 28-39, Feb. 2002

[4] L. Oscar, P. Henriques, L. G. Rolim, P. Branco, W. Suemitsu, " Review of the ripple reduction strategies in SRM", Brazilian Congress of Automatic Christmas, 2 to 5 September 2002 .

[5] E.El-Kharashi, "Design and predicting efficiency of highly nonlinear hollow cylinders switched reluctance motor", Energy Conversion and Management, 48 , pp. 2261-2275,2007. 
[6] H.Shang and T.Ching," A Novel Switched Reluctance Motor With C-Core Stators", IEEE Transactions on magnetic, Vol. 41, No. 12, pp. 44134420, DEC., 2005.

[7] F. Daldaban, N. Ustkoyuncu “ Multi-layer switched reluctance motor to reduce torque ripple ", Energy Conversion and Management, 49, pp. 974-979, 2008.

[8] M. Rodrigues, P.J. Costa Branco and W. Suemitsu. "Fuzzy Logic Torque Ripple by Turn-Off Angle Compensation for Switched Reluctance Motors", IEEE Transactions on Industry Electronics, Vol. 48, No. 3, , pp.711-714, JUNE 2001.

[9] H. Zhang, J. Zhang, R. Gao,"A Novel Method of Phase Current Compensation for Switched Reluctance Motor System Based on Finite Element', Journal of computers, vol. 4, No. 10, OCT. 2009.

[10] W. Shang, Sh. Zhao, Y. Shen, and Ziming," A Sliding Mode Flux-Linkage Controller with Integral Compensation for Switched Reluctance Motor", IEEE transaction on magnetic, vol.45, no. 9, pp.3322-3328, SEP 2009.

[11] L. Oscar, P. J. Branco, L. Guilherme, W.Issamu, "Proposition of an Offline Learning Current Modulation for Torque-Ripple Reduction in Switched Reluctance
Motors: Design and Experimental Evaluation", IEEE transaction on industrial electronics, vol. 49, no. 3,pp. 665-676, June 2002.

[12] M. Ali Akcayol, C. Elmas "NEFCLASS-based neuro fuzzy controller for SRM drives", Engineering Applications of Artificial Intelligence ,18 , pp. 595602,2005

[13] Afjei Toliyat," A novel multilayer switched reluctance motor", IEEE Transaction on Energy Conversion Vol. 17, No. 2,pp.217-221, JUNE 2002

[14] J.Jang, “ANFIS: adaptive-network-based fuzzy inference system", IEEE Trans Syst Man Cybernet Vol. 23, No.3, pp. 665-685, MAY/JUNE 1993.

[15] J. Jang, C. Sun, E. Mizutani "Neuro-fuzzy and soft computing: a computational approach to learning and machine intelligence" Upper Saddle River: PrenticeHall; 1997.

[16] MATLAB, Users guide: fuzzy logic toolbox, The Mathworks Inc; 2011.

[17] F. Soares, P.J. Costa Branco, "Simulation of a 6/4 switched reluctance motor based on Matlab/Simulink environment", IEEE transaction on aerospace and electronic systems, vol. 37 ,no. 3, pp.989-1009, July 2002. 